\title{
Characteristics and Determinants of Patients Discontinuation of Breast Cancer Follow-Up Care at the Radiation Oncology Department, University College Hospital, Ibadan, Nigeria
}

\author{
M. D. Dairo ${ }^{1},{ }^{1}$ D. B. Adamu, ${ }^{2,3}$ Y. A. Onimode, ${ }^{4}$ A. Ntekim, ${ }^{2}$ and O. Ayeni1 \\ ${ }^{1}$ Department of Epidemiology and Medical Statistics, Faculty of Public Health, College of Medicine, University of Ibadan, Nigeria \\ ${ }^{2}$ Department of Radiation Oncology, University College Hospital Ibadan, Nigeria \\ ${ }^{3}$ Department of Radiology, Gombe State University, Nigeria \\ ${ }^{4}$ Nuclear Unit, Department of Radiation Oncology, College of Medicine, University of Ibadan, Nigeria
}

Correspondence should be addressed to M. D. Dairo; drdairo@yahoo.com

Received 1 June 2018; Accepted 22 July 2018; Published 12 August 2018

Academic Editor: Vladimir F. Semiglazov

Copyright (C) 2018 M. D. Dairo et al. This is an open access article distributed under the Creative Commons Attribution License, which permits unrestricted use, distribution, and reproduction in any medium, provided the original work is properly cited.

\begin{abstract}
Objectives. The aim of this study is to describe the characteristics and predictors of discontinuation during follow-up care among breast cancer patients at the Radiation Oncology Department, University College Hospital (UCH), Ibadan, Nigeria. Methodology. This is a retrospective cross-sectional study of 504 patients with histological diagnosis of breast cancer referred for radiotherapy to the breast or chest wall. Data extraction form was used to obtain information on sociodemographic and disease related variables and time to discontinuation of care. Discontinuation rates and its predictors were estimated using Kaplan-Meier, Log rank test, and Cox's regression method of analyses. Results. Five hundred and four breast cancer patients were studied. The mean age was 47.7years, $58.2 \%$ presented late with advanced stage disease, and $40 \%$ and $39 \%$ had metastasis and anaemia, respectively. Seventyseven percent of patients discontinued follow-up care before completion of ten-year period. The 5-year and 10-year discontinuation rates were $69.8 \%$ and $92.6 \%$, respectively. The median discontinuation time was 44 months. Discontinuers were more likely to be older than the age of 45years $\{\mathrm{HR}=1.415 ; 95 \% \mathrm{CI}=1.044-1.917\}$, have metastasis $\{\mathrm{HR}=1.793 ; 95 \% \mathrm{CI}=1.396-2.302\}$, be anaemic $\{\mathrm{HR}=1.404 ; 95 \% \mathrm{CI}=1.120-1.760)\}$, and have late-stage disease $\{\mathrm{HR}=1.310 ; 95 \% \mathrm{CI}=1.407-1.639)\}$. Conclusion. Breast cancer care discontinuation is associated with late presentation and advanced stage of disease. Therefore a system of community follow-up care and public awareness about breast cancer symptoms is recommended to reduce late presentation and discontinuity of care.
\end{abstract}

\section{Introduction}

Breast cancer is the leading female malignancy in the world and is now the most common cancer in Nigeria [1]. The peak incidence of the disease in Nigeria is at least a decade earlier compared to the Caucasians [2]. The incidence of breast cancer in Nigeria is on the increase from 13.8 to 15.3 per 100,000 in 1992 to 116 per 100,000 in 2001 in Ibadan [3].

The major constraint in the management of breast cancer in Nigeria is the limitation of resources because patients bear the burden of paying for cancer treatment. Having a population of over 180 million and a Gross Domestic Product of about 2000US Dollar per capital annually, Nigeria ranks among the poorest nations in the world. The National Health
Insurance Scheme is still in its formative stage; thus payment for cancer treatment is mostly out of pocket. Thus a significant proportion of patients do not present for treatment, may not complete the prescribed courses of treatment, and do not attend posttherapy surveillance, the follow-up care required to maintain better health status, assess effectiveness of therapy, and detect and treat early recurrence of the disease [4]. Recent study in Ibadan reported that majority of breast cancer recurrences were detected within 2 years of primary treatment, indicating the necessity of follow-up evaluations [5].

Loss to follow-up is a major challenge in the successful management of breast cancer patients in Nigeria and subSaharan Africa; true outcomes of patients lost to followup thus become difficult to assess. In Nigeria, as indeed in 
many developing countries, a combination of poor education, poverty, and a high percentage of nonorthodox healing practices among the populace contribute to late presentation of breast cancer in many hospitals with consequent high occurrence of metastatic disease and poor disease survival [6]. This is worsened by the commonly encountered nonadherence to treatment schedule among the patients. The burden of caring for these large numbers of patients in a low resource country is enormous.

There are five functional radiotherapy centres in Nigeria today with a population of over 150 million. This gives a ratio of one radiotherapy centre to about 30 million persons, a far cry from the WHO recommendation of 1: 250,000 persons [7]. Thus patients will have to travel long distances for radiotherapy. Longer distances imply more financial burden on the patient's caregivers; the family members who have to take more time off from work suffer loss of pay and incur the costs of feeding, travelling, and accommodation at the referral hospital. Such expenditure can be sufficiently enormous to discourage the patient from adherence to routine follow-up care. The benefits of follow-up in breast cancer patients include early detection of potentially curable events, management of therapy related side effects, psychosocial care, support and counselling, encouragement and support for physical exercise, and weight reduction during follow-up in order to improve quality of life and physical performance, reevaluation of current adjuvant therapy, and monitoring of compliance with endocrine therapies. However, these benefits are missed by patients discontinuing follow-up.

Most studies on breast cancer in Nigeria emphasized pathology, epidemiology, and clinical features of the disease with few attempts at determining survival among these patients $[1,3,5,8-11]$. It is essential to target this group of patients and understand the sociodemographic and disease related barriers to posttherapy follow-up in order to provide strategic interventions to prevent loss to follow-up and a better patient outcome. The aim of this study therefore was to define the characteristics of breast cancer patients and identify determinants or predictors of discontinuation of follow-up care among them.

\section{Methodology}

2.1. Study Setting. The study was carried out at the Radiotherapy Clinic, University College Hospital (UCH), Ibadan, Nigeria. Radiotherapy department was established in the year 1987. It is equipped with a Telecobalt and HDR Co60 Brachytherapy machines with modern treatment planning system. The department has 6 Radiation Oncologists and 2 certified medical Physicists. It serves as a referral centre for cancer patients that require radiation therapy from units within UCH and clinics and hospitals within and outside Ibadan (patients from all over the country including some West African countries). Annually the department treats about 200-300 breast cancer patients. The study population consists of patients with histological diagnosis of breast cancer referred for radiotherapy to the breast or chest wall.
2.2. Study Design. This is a retrospective cross-sectional study on breast cancer patient's follow-up. The study participants included breast cancer patients with histological diagnosis referred for adjuvant radiotherapy of the breast or chest wall at the Radiotherapy Department, UCH, Ibadan, over a period of ten years. The records of the following categories of patients were excluded from the study: breast cancer cases without accompanying histological confirmation of diagnosis and breast cancer cases without case file or radiotherapy treatment cards and without at least one follow-up record.

2.3. Data Collection Instrument and Procedures. Hospital case files with follow-up records and radiotherapy treatment cards of breast cancer patients attended to between 2001 and 2010 were retrieved from the radiotherapy clinic medical records by the investigators. The data was collected using a data extraction form which consist of age at diagnosis, sex, educational status, marital status, menopausal status, parity, stage of breast cancer at diagnosis (Manchester staging classification was used as it is the commonest staging classification used by surgeons referring patients for radiotherapy outside of Ibadan), grade of differentiation, histology of breast cancer, lymph node status, development of metastasis, duration of symptoms before diagnosis, distance of home town from University College Hospital, Ibadan (in kilometers), surgery performed (no surgery, breast conservation surgery or radical surgery), whether patient received adjuvant chemotherapy or radiotherapy to the chest wall, baseline packed cell volume (PCV), and status of patient from diagnosis to discontinuation of follow-up. The status was either loss to follow-up or censored (survival beyond end of study or death) and time to event, that is, loss to follow-up in months.

2.4. Data Management and Analysis. The data were carefully entered and analyzed using SPSS version 16.0. Regular checks were done to detect and correct errors. The dependent or the outcome variable was defined as the time from histological diagnosis to discontinuation of follow-up care. Discontinuation of care is defined as missing three consecutive followup appointments. The independent variables explored are the sociodemographic characteristics and clinical factors such as age, distance of home town from the University College Hospital, marital status, duration of disease symptoms before diagnosis, educational status, stage of disease, baseline PCV, and metastasis. Frequency, percentage, mean, median, range, and standard deviation were used to summarize the sociodemographic, clinical, and treatment variables of the patients and presented using tables and graphs. Discontinuation curves were plotted using Kaplan-Meier method and curves were compared using Log rank test. Log rank test was used to test for an association between dependent variable (loss to follow-up) and independent variables such as age, marital status, educational status, menopausal status, duration of symptom before diagnosis, distance of home/town to $\mathrm{UCH}$, Ibadan, stage of disease at presentation, lymph node status, histological grade, metastasis, and anaemia. The variables were considered to show significant association when the $\mathrm{p}$ value was less than 0.05 . The discontinuation of 
patients with breast cancer was compared using Log rank test according clinical features. The clinical features were dichotomized for ease of comparison between the clinical subgroups. Multivariate analysis was carried out using Coxproportional hazard models to determine the predictors of discontinuation of follow-up. This was done using covariates that showed statistically significant association with followup discontinuation at $\mathrm{p}<0.1$ on bivariate analysis. In analysis of discontinuation using Kaplan-Meier, time of origin was taken as the time of breast cancer diagnosis. The patient status at 31st December, 2010, was categorized as alive, dead, and lost to follow-up. The endpoint of patient was follow-up discontinuation. Patient that died before or found alive at end of December 2010 was censored. The median discontinuation times were obtained from the Kaplan-Meier discontinuation curve.

Multivariate Cox's proportional hazard model is expressed as follows:

$$
h(t, X)=h_{0}(t) \exp \left(\sum_{i=1}^{p} \beta_{i} x_{i}\right)
$$

where

$X=\left(x_{1}, x_{2}, \cdots, x_{p}\right)$ is explanatory/predictor variables;

$h_{0}(t)$ is baseline function (the hazard function for an individual for whom all the values of the independent variables are zero);

$\beta$ is the vector of coefficients of the independent variables $X_{i}$.

The general Cox's proportional hazard model was fitted for the following: age, marital status, stage of disease, PCV status, duration of symptoms, distance of home/town from Ibadan, and metastasis. They were statistically significant in the Log rank test.

The proportional hazard model now becomes

$$
\begin{aligned}
& h(t)=h_{0}(t) \exp \left(\beta_{1} \text { Age }+\beta_{2}\right. \text { Anaemia } \\
& +\beta_{3} \text { stage of disease }+\beta_{4} \text { Metastasis } \\
& +\beta_{5} \text { Marital status }+\beta_{6} \text { Menopausal status } \\
& +\beta_{7} \text { Duration of symptoms } \\
& \left.+\beta_{8} \text { Distance of home from Ibadan }\right)
\end{aligned}
$$

2.5. Ethical Consideration. Ethical clearance to conduct the study was obtained from the joint Ethical Review committee of the University of Ibadan/University College Hospital, Ibadan. All information collected in this study were coded with numbers and hospital numbers and the names of patients were not used to maintain confidentiality. The data extraction forms were kept in a locked cupboard; the data entered on the computer were password protected and are accessible to the researcher only. During the study, there was no contact between the patients and the researcher. The study was noninvasive and without any harm to the patients.

\section{Results}

3.1. Patients Sociodemographic Characteristics. A total of 504 (Females: $n=500$, Males: $n=4$ ) patients satisfied the inclusion criteria. Table 1 showed that the mean age of patients was 47.69 years with a standard deviation of 10.63 . Most of the patients are between the ages of 41 and 50 years (34.1\%); the mean age is $61.25 \%$ for males and $47.58 \%$ for females, respectively. The majority of women with breast cancer were postmenopausal $272(54.0 \%)$, while $216(42.9 \%)$ were premenopausal and 16 (3.2\%) had unknown menopausal status.

3.2. Patients Clinical Characteristics. The commonest site of breast cancer was on the left breast [244, (48.4\%)] while the right breast accounted for about 227 (45.0\%) and 33 (6.5\%) of breast cancer was seen in both breasts during the study. Stages I, II, III, and IV accounted for 29 (5.8\%), 177 (35.1\%), 138(27.4\%), and 155 (30.8\%), respectively. Early-stage breast cancer (stages I\&II) accounted for $40.9 \%$ while late-stage breast cancer (stages III\&IV) constituted the majority. Most of patients $(86.5 \%)$ had positive auxiliary nodes; ipsilateral axilla was seen in $84(16.7 \%)$. Status of axillary nodes could not be determined in $24(4.8 \%)$ of patients.

Invasive ductal carcinoma [443, (87.9\%)] accounted for the most common histological type of breast cancer seen. Grade II breast cancer was also the most common, being seen in 303 (60.1\%) of the cases, while 202(40.1\%) had distant metastases. The metastasis was more commonly found in the bone $(116,23.0 \%)$ and the lungs [104, (20.6\%). Three hundred and ten patients $(61.5 \%)$ had a normal $\mathrm{PCV} \geq 33 \%)$ at baseline before treatment while 194 (38.5\%) had low packed cell volume (PCV <33\%). Most of the women with breast cancer underwent radical breast surgery [413, (81.9\%)]. Almost all the patients completed chemotherapy and radiotherapy but more than half $[268,(53.2 \%)]$ did not complete hormonal therapy (Table 2).

3.3. Factors Associated with Discontinuation of Follow-Up Care. Table 3 shows the comparison of the estimation of the median time to discontinue care among the patients. At the bivariate analysis the marital status ( $\mathrm{p}=0.004)$, duration before diagnosis $(p=0.027)$ and stage of disease before presentation $(p<0.001)$, presence of metastasis $(p<0.001)$, and baseline packed cell volume $(\mathrm{p}<0.001)$ were all associated with the median time to discontinuation of care. Those who presented with late-stage disease, had metastasis, and had anaemia were more likely to discontinue follow-up care earlier than others (Figures 1-3).

3.4. Predictors of Discontinuation of Breast Cancer Care. The multivariate analysis was done using Cox-proportional hazard model using covariates that showed statistically significant association with loss to follow-up at $\mathrm{p}<0.1$ from KaplanMeier method and Log rank test. Table 4 showed the results of the Cox-proportional hazard model on variables associated with discontinuation of follow-up. Patients with metastasis $[\mathrm{HR}=1.793 ; 95 \% \mathrm{CI}=1.396-2.302]$, anaemia $[\mathrm{HR}=1.404 ; 95 \%$ $\mathrm{CI}=1.120-1.760]$, advanced/late-stage disease $[\mathrm{HR}=1.310$; $95 \% \mathrm{CI}=1.047-1.639]$, and of older age $[\mathrm{HR}=1.415 ; 95 \% \mathrm{CI}$ 
TABLE 1: Sociodemographic characteristics of breast cancer patients seen at UCH, Ibadan,2001-2010.

\begin{tabular}{|c|c|c|c|c|}
\hline Variable & Study group & Non study group $t$ & & p value \\
\hline No of patients & $\mathrm{n}=504$ & $\mathrm{n}=518$ & & \\
\hline \multicolumn{5}{|l|}{ Age } \\
\hline Mean & $47.69 \pm 10.63$ & $48.15 \pm 11.44$ & -0.666 & 0.506 \\
\hline \multicolumn{5}{|l|}{ Sex } \\
\hline Male & $4(0.8 \%) \quad 5(1.0 \%)$ & & & \\
\hline Female & $500(99.2 \%)$ & $513(99.0 \%)$ & & \\
\hline Variable & Frequency (\%) & & & \\
\hline \multicolumn{5}{|c|}{ Age groups distribution. } \\
\hline$\leq 30$ & $13(2.6 \%)$ & & & \\
\hline $31-40$ & $134(26.6 \%)$ & & & \\
\hline $41-50$ & $172(34.1 \%)$ & & & \\
\hline $51-60$ & $122(24.2 \%)$ & & & \\
\hline $61-70$ & $60(11.9 \%)$ & & & \\
\hline$>70$ & $3(0.6 \%)$ & & & \\
\hline \multicolumn{5}{|l|}{ Educational status } \\
\hline None & $182(36.1 \%)$ & & & \\
\hline Below primary & $8(1.6 \%)$ & & & \\
\hline Primary school & $41(8.1 \%)$ & & & \\
\hline Secondary school & $117(23.2 \%)$ & & & \\
\hline Tertiary & $156(31.0 \%)$ & & & \\
\hline \multicolumn{5}{|l|}{ Marital status } \\
\hline Single & $23(4.6 \%)$ & & & \\
\hline Married & $412(81.7 \%)$ & & & \\
\hline Divorced & $7(1.4 \%)$ & & & \\
\hline Separated & $1(0.2 \%)$ & & & \\
\hline Widow & $44(8.7 \%)$ & & & \\
\hline Unknown & $17(3.4 \%)$ & & & \\
\hline \multicolumn{5}{|l|}{ Parity } \\
\hline Nulliparity & $33(6.5 \%)$ & & & \\
\hline Multiparity & $230(45.6 \%)$ & & & \\
\hline Grand multiparity & $231(45.8 \%)$ & & & \\
\hline Unknown & $10(2.0 \%)$ & & & \\
\hline \multicolumn{5}{|c|}{ Distance from home town to $\mathrm{UCH}$, Ibadan } \\
\hline$\leq 250 \mathrm{KM}$ & $274(54.4 \%)$ & & & \\
\hline$>250 \mathrm{KM}$ & $230(45.6 \%)$ & & & \\
\hline \multicolumn{5}{|c|}{ Duration of symptoms before diagnosis } \\
\hline$\leq 12$ months & $370(73.4 \%)$ & & & \\
\hline$>12$ months & $134(26.6 \%)$ & & & \\
\hline \multicolumn{5}{|l|}{ Menopausal Status } \\
\hline Menopausal & $272(54.0 \%)$ & & & \\
\hline Premenopausal & $216(42.9 \%)$ & & & \\
\hline Unknown & $16(3.2 \%)$ & & & \\
\hline
\end{tabular}

$=1.044-1.917]$ are significantly more likely to discontinue follow-up early.

\section{Discussion}

The incidence and mortality of breast cancer are falling in the developed world due to early detection and improved treatment methods while, in the developing countries like
Nigeria, the opposite is the case. It is an irony of life that cancer in women in the most accessible organ of the body and the one that epitomizes womanhood commonly presents late in Nigeria with advanced stage disease and overwhelming local and systemic metastases.

This study revealed a mean age of patients with breast cancer studied to be 47.69 years with a standard deviation of 10.26 and the peak age of occurrence at 40-49 years. 
TABLE 2: Clinical characteristics of breast cancer patients seen at UCH, Ibadan, 2001-2010.

\begin{tabular}{|c|c|}
\hline Variable & Frequency $(\%)$ \\
\hline \multicolumn{2}{|l|}{ Site of disease } \\
\hline Right & $227(45.0 \%)$ \\
\hline Left & $244(48.4 \%)$ \\
\hline Bilateral & $33(6.5 \%)$ \\
\hline \multicolumn{2}{|l|}{ Stage of disease (Manchester staging) } \\
\hline I & $29(5.8 \%)$ \\
\hline II & $177(35.1 \%)$ \\
\hline III & $138(27.4 \%)$ \\
\hline IV & $155(30.8 \%)$ \\
\hline Unknown & $5(1.0 \%)$ \\
\hline \multicolumn{2}{|l|}{ Lymph node status } \\
\hline No axillary nodes & $62(12.3 \%)$ \\
\hline Nodes limited to ipsilateral axilla & $334(66.3 \%)$ \\
\hline Nodes beyond ipsilateral axilla & $84(16.7 \%)$ \\
\hline Unknown & $24(4.8 \%)$ \\
\hline \multicolumn{2}{|l|}{ Histological type } \\
\hline Invasive ductal carcinoma & $443(87.9 \%)$ \\
\hline Invasive lobular carcinoma & $23(4.6 \%)$ \\
\hline Inflammatory breast cancer & $10(2.0 \%)$ \\
\hline Breast sarcoma & $2(0.2 \%)$ \\
\hline Anaplastic carcinoma & $3(0.6 \%)$ \\
\hline Malignant cystosarcoma phylloides & $4(0.8 \%)$ \\
\hline Mucinous carcinoma & $5(1.0 \%)$ \\
\hline Squamous cell carcinoma & $4(0.8 \%)$ \\
\hline Paget's disease & $2(0.2 \%)$ \\
\hline Others & $8(1.6 \%)$ \\
\hline \multicolumn{2}{|l|}{ Histological grade } \\
\hline I & $89(17.7 \%)$ \\
\hline II & $303(60.1 \%)$ \\
\hline III & $84(16.7 \%)$ \\
\hline Unknown & $28(5.6 \%)$ \\
\hline \multicolumn{2}{|l|}{ Surgery } \\
\hline No surgery & $34(6.7 \%)$ \\
\hline Radical surgery & $413(81.9 \%)$ \\
\hline Breast conservation surgery & $57(11.3 \%)$ \\
\hline \multicolumn{2}{|l|}{ Completed chemotherapy } \\
\hline Yes & $498(98.8 \%)$ \\
\hline No & $6(1.2 \%)$ \\
\hline \multicolumn{2}{|l|}{ Completed radiotherapy } \\
\hline Yes & $493(97.8 \%)$ \\
\hline No & $11(2.2 \%)$ \\
\hline \multicolumn{2}{|l|}{ Completed hormonal therapy } \\
\hline Yes & $236(46.8 \%)$ \\
\hline No & $268(53.2 \%)$ \\
\hline \multicolumn{2}{|l|}{ Developed metastasis } \\
\hline Yes & $202(40.1 \%)$ \\
\hline No & $302(59.9 \%)$ \\
\hline \multicolumn{2}{|l|}{ Sites of metastasis } \\
\hline Lungs & $104(20.6 \%)$ \\
\hline Bone & $116(23.0 \%)$ \\
\hline Liver & $40(7.9 \%)$ \\
\hline Brain & $26(5.2 \%)$ \\
\hline Kidney & $1(0.2 \%)$ \\
\hline \multicolumn{2}{|l|}{ Baseline packed cell volume (PCV) } \\
\hline Low $(\mathrm{PCV}<33 \%)$ & $194(38.5 \%)$ \\
\hline Normal (PCV $\geq 33 \%)$ & $310(61.5 \%)$ \\
\hline
\end{tabular}

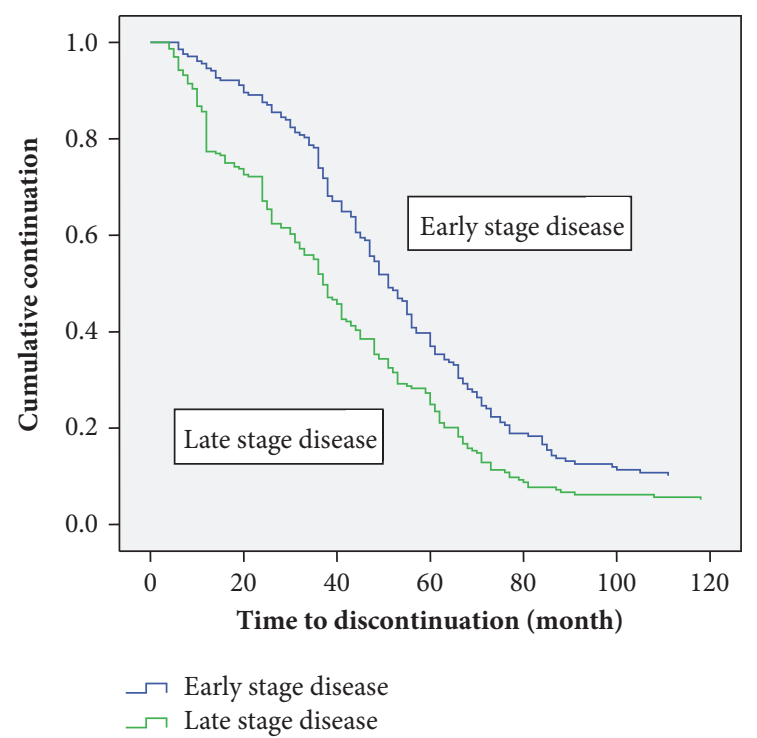

FIgURE 1: Kaplan Meier discontinuation curve by Manchester stage.

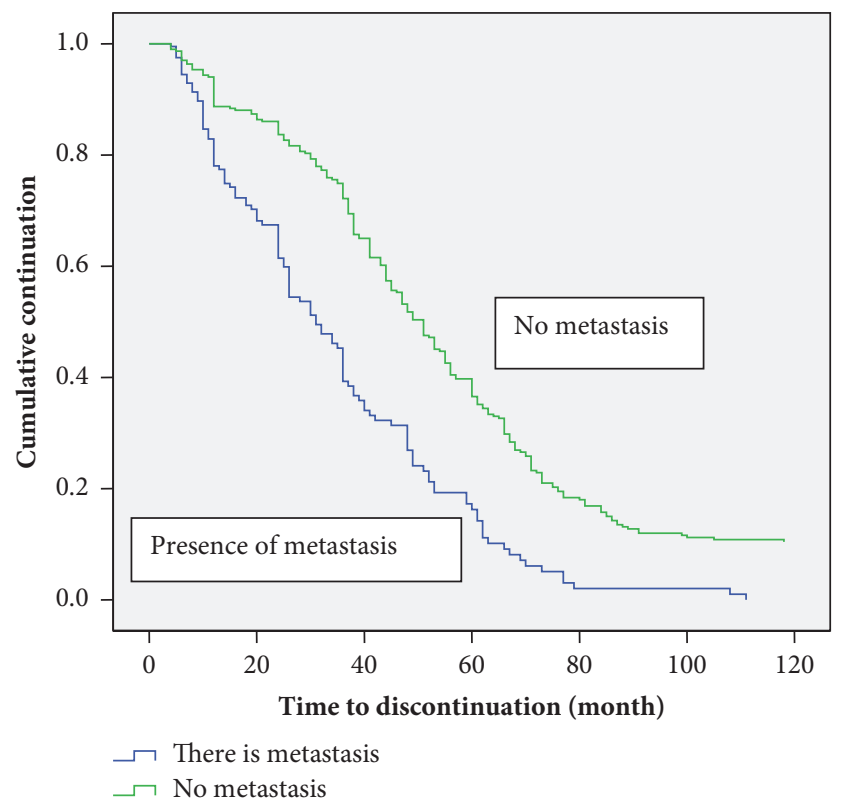

FIGURE 2: Kaplan-Meier discontinuation curve by metastasis.

Adesunkanmi in a study at Ile-Ife, Nigeria, found similar demographics of breast cancer patients with a mean age of 48 years, standard deviation of 12.3 , and peak age of $40-49$ years [3]. The results are also consistent with the findings of Emmanuel and Obaseki from Niger Delta of Nigeria [12]. Bird and colleagues reported a mean age of 48 years from Kenya while Saghir et al. reported a mean age of 47 years from Beirut, Lebanon [13, 14]. However, Massimo reported a mean age of 58.0 from the United States of America [15]. This reiterates the fact that breast cancer patients in this environment are a decade younger than those in Caucasians.

Male breast cancer accounted for $0.8 \%$ of cases of breast cancer studied; this differs from previous studies done in 
TABLE 3: Log rank test estimation of discontinuation of breast cancer patients by clinical features, at UCH, Ibadan, $2001-2010$.

\begin{tabular}{|c|c|c|c|c|c|}
\hline Variable & $\begin{array}{c}\text { MDT } \\
\text { (months) }\end{array}$ & $\begin{array}{c}\text { Log rank } \\
\text { Chi-square }\end{array}$ & $\mathrm{SE}[\mathrm{s}(\mathrm{t})]$ & $95 \% \mathrm{CI}$ & $\mathrm{P}$ value \\
\hline \multicolumn{6}{|l|}{ Age } \\
\hline Younger patients & 44.0 & 3.498 & 2.965 & $38.18-49.81$ & \multirow{2}{*}{0.061} \\
\hline Older patients & 44.0 & & 2.325 & $39.44-48.56$ & \\
\hline \multicolumn{6}{|l|}{ Educational level } \\
\hline Primary school and below & 41.0 & 1.053 & 2.195 & $36.70-45.30$ & \multirow{2}{*}{0.305} \\
\hline Secondary school and above & 47.0 & & 2.265 & $42.60-51.40$ & \\
\hline \multicolumn{6}{|l|}{ Marital status } \\
\hline Not married & 39.0 & 8.289 & 2.315 & $34.50-43.50$ & \multirow{2}{*}{0.004} \\
\hline Married & 45.0 & & 1.954 & $41.20-48.80$ & \\
\hline \multicolumn{6}{|l|}{ Menopausal status } \\
\hline Premenopausal & 44.0 & 2.965 & 3.356 & $39.40-52.60$ & \multirow{2}{*}{0.085} \\
\hline Postmenopausal & 45.0 & & 1.876 & $41.30-48.70$ & \\
\hline \multicolumn{6}{|c|}{ Duration of symptoms before diagnosis } \\
\hline Up to 12 months & 47.0 & 4.868 & 2.233 & $42.60-51.40$ & \multirow{2}{*}{0.027} \\
\hline Above 12 months & 37.0 & & 1.914 & $33.20-40.8$ & \\
\hline \multicolumn{6}{|c|}{ Distance of home town to $\mathrm{UCH}$ to Ibadan } \\
\hline$>250 \mathrm{KM}$ & 46.0 & 0.282 & 2.252 & $41.60-50.40$ & \multirow{2}{*}{0.596} \\
\hline$\leq 250 \mathrm{KM}$ & 41.0 & & 2.772 & $35.60-46.40$ & \\
\hline \multicolumn{6}{|l|}{ Stage of disease } \\
\hline Early stage (I\&II) & 51.0 & 19.500 & 2.416 & $46.30-55.70$ & \multirow{2}{*}{$<0.001$} \\
\hline Late stage (III\&IV) & 37.0 & & 1.542 & $34.00-40.00$ & \\
\hline \multicolumn{6}{|l|}{ Axillary node status } \\
\hline No axillary nodes & 51.0 & 1.600 & 6.717 & $38.00-64.00$ & \multirow{2}{*}{0.198} \\
\hline Presence of axillary nodes & 44.0 & & 2.023 & $40.00-48.00$ & \\
\hline \multicolumn{6}{|l|}{ Grade of differentiation } \\
\hline Well differentiated & 41.0 & 1.360 & 2.729 & $35.70-46-30$ & \multirow{2}{*}{0.244} \\
\hline Moderate/poorly differentiated & 45.0 & & 2.334 & $40.40-49.60$ & \\
\hline \multicolumn{6}{|l|}{ Metastasis } \\
\hline Presence of metastasis & 31.0 & 49.761 & 2.233 & $26.60-35.40$ & \multirow{2}{*}{$<0.001$} \\
\hline No metastasis & 51.0 & & 2.213 & $46.70-55.30$ & \\
\hline \multicolumn{6}{|l|}{ Baseline packed cell volume } \\
\hline Low PCV & 38.0 & 18.775 & 2.147 & $33.80-42.20$ & \multirow{2}{*}{$<0.001$} \\
\hline Normal PCV & 47.0 & & 2.183 & $42.70-51.30$ & \\
\hline
\end{tabular}

$\mathrm{MDT}=$ median discontinuation time; $\mathrm{CI}=$ confidence interval; $\mathrm{SE}=$ standard error.

Ibadan and Eastern Nigeria by Ogundiran et al. and Dogo et al., where they reported $2.9 \%$ and $3.7 \%$, respectively $[16,17]$. Our finding is consistent with that of Caucasians where less than $1 \%$ are reported $[18,19]$.

This study showed that $6.5 \%$ are nulliparous while the majority $91.4 \%$ are either multiparous or grand multiparous. This finding is contrary to the report by other investigators who had reported that the higher the number of full-term pregnancies, the greater the protection from breast cancer. A reduction in the risk of breast cancer by $7 \%$ for had been reported for each birth after the first, in the absence of breastfeeding. In addition, women who breastfeed reduce their risk compared to those who do not [11].

The mean duration of symptoms before diagnosis of 11.64 months. This constitutes late presentation. Bray et al. emphasized that prognosis is heavily dependent on stage of disease at presentation [20]. Late presentation with advanced stage of disease (stages III \& IV) was seen in $58.2 \%$ of the patients studied; unfortunately when compared to earlier studies from Nigeria and sub-Saharan Africa, the outlook remained poor [3, 5, 21-23]. Adesunkanmi, 2006, reported a similar duration of 11.2 months and about $83 \%$ of these patients have detectable axillary nodes limited to or beyond ipsilateral axilla by the time of presentation [3]. The late presentation with advanced disease in this study can be explained by a myriad of factors, such as the low and poor level of education and the far distance of the residences of these patients from the referral centre. In this study more than two-thirds (69\%) of the patients were not educated beyond secondary level. The low education level may lead to poor 
TABLE 4: Cox regression analysis of hazard ratios of predictors of discontinuation of breast cancer patients seen at UCH, Ibadan, 2001-2010.

\begin{tabular}{|c|c|c|c|}
\hline Variable & HR & 95\%CI & P-value \\
\hline \multicolumn{4}{|l|}{ Development of metastasis } \\
\hline There is metastasis & 1.793 & \multirow{2}{*}{$1.396-2.302$} & \multirow{2}{*}{$<0.001$} \\
\hline No metastasis & 1.00 & & \\
\hline \multicolumn{4}{|c|}{ Baseline packed cell volume (PCV) } \\
\hline Low (anaemia) & 1.404 & \multirow{2}{*}{$1.120-1.760$} & \multirow{2}{*}{0.005} \\
\hline Normal (no anaemia) & 1.00 & & \\
\hline \multicolumn{4}{|c|}{ Stage at presentation (Manchester stage) } \\
\hline Early stage (Stage I\&II) & 1.310 & \multirow{2}{*}{$1.047-1.639$} & \multirow{2}{*}{0.015} \\
\hline Late stage (Stage III\&IV) & 1.00 & & \\
\hline \multicolumn{4}{|c|}{ Duration of symptoms before diagnosis } \\
\hline$\leq 12$ months & 0.833 & \multirow{2}{*}{$0.660-1.051$} & \multirow{2}{*}{0.123} \\
\hline$>12$ months & 1.00 & & \\
\hline \multicolumn{4}{|l|}{ Menopausal status } \\
\hline Premenopausal patients & 1.063 & \multirow{2}{*}{$0.794-1.425$} & \multirow{2}{*}{0.680} \\
\hline Postmenopausal patients & 1.00 & & \\
\hline \multicolumn{4}{|l|}{ Age } \\
\hline Younger patients & 1.415 & \multirow{2}{*}{$1.044-1.917$} & \multirow{2}{*}{0.52} \\
\hline Older patients & 1.00 & & \\
\hline \multicolumn{4}{|l|}{ Marital status } \\
\hline Not Married & 1.256 & \multirow{2}{*}{$0.964-1.637$} & \multirow{2}{*}{0.091} \\
\hline Married & 1.00 & & \\
\hline
\end{tabular}

$\mathrm{CI}$ = confidence interval; $\mathrm{HR}=$ hazard ratio; 1.00 = reference category.

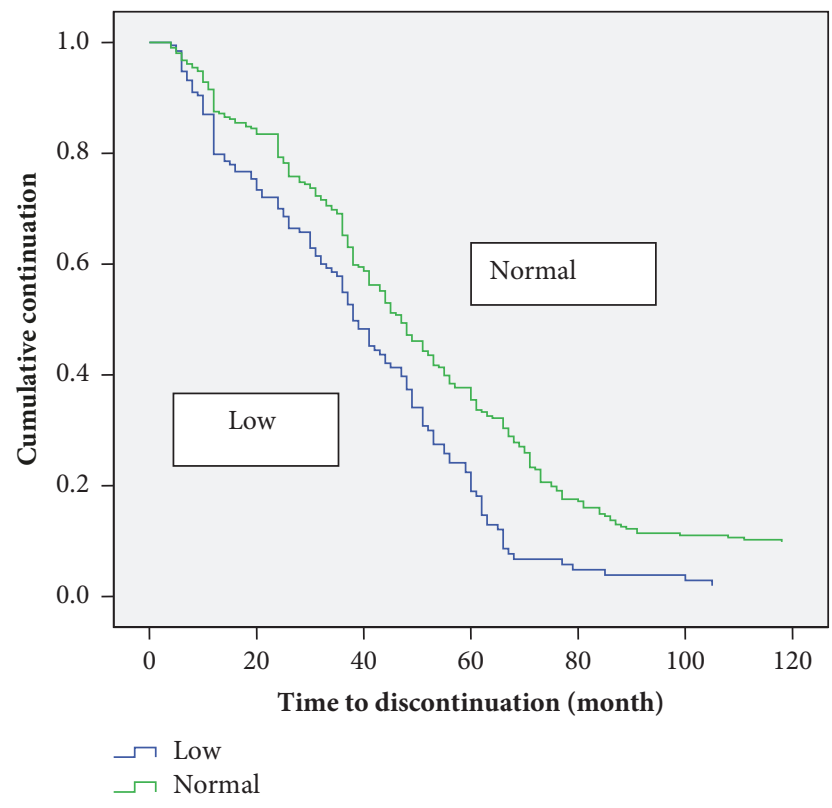

Figure 3: Kaplan-Meier discontinuation curve by PCV status.

understanding of symptoms and compliance with measures at early detection and presentation. In addition almost half of the patients came from far places in Nigeria outside South Western states. The far distances could also be the reason for late presentation at the referral centre.
About $40 \%$ of patients in this study had metastasis, which is explainable by the fact that large number of these patients presented late with advanced disease and had palpable axillary nodes within and beyond axilla, a significant proportion (about 40\%) presenting for the first time with anaemia. Adisa, 2011, reported a higher figure of $52 \%$ with metastasis from Ile-Ife while Bray reported 26\% from the United States of America [20-25]. Racial differences in the tumour biology of breast cancer are seen in Nigerians and African Americans compared to Caucasians points to possible differences in the aetiology or in the genetic makeup of the two cases. The tumours in blacks tend to be more aggressive because most tumours diagnosed among blacks are oestrogen receptor negative (ER negative) and ER negative tumours tend to be poorly differentiated with shorter doubling time $[25,26]$. ER receptor status could not be determined because it is not routinely tested for in $\mathrm{UCH}$, Ibadan, due to limited resources. A significant proportion of these patients (about $40 \%)$ presented with anaemia; this is probably due to the larger number of patients with advanced disease in this study. These patients have bulky disease and high tumour burden in their bodies resulting in recurrent bleeding, excessive increase in metabolic demand, and poor intake due to repeated ill health.

This study found that the predictors of discontinuation among breast cancer patients on follow-up care and therapy include having an advanced stage disease with distant organ metastasis and anaemia. In the studies by Misu, Preethi, and Matthew, from India and Mangardich from South Bronx, 
the poorest district of the US reported a similar significant association of higher and poor disease burden with loss to follow-up [27, 28]. In the present analysis, patients with metastasis and anaemia were more likely to be lost to followup. As the disease progresses, and as the patient grows more dependent, more support is needed to keep up with follow-up care. This assertion is corroborated with the findings by Kaku et al. and Misu and Matthew who observed similar trends among patients with advanced stage cervical cancer in India $[26,29]$. Thus patients without metastasis and anaemia and better performance status were more likely and more able to follow through with their care.

This study also found that older patients are more likely to discontinue follow-up care early. This is because older patients may be more dependent on others, may be less assertive due to the realization of inevitability of death at such an advanced age, and would like to avoid further painful treatment. However, younger patients may be more capable and can attend some of the visits on their own without depending on other family members. Fink, Kahn, and Onwusu, in their independent studies, had identified older age as a predictor of discontinuation of care among breast cancer patients on follow-up therapy [30-32]. Overall, follow-up discontinuation among breast cancer patients that are older and anaemic with advanced stage disease and metastasis might be explained by death. These patients have high disease burden that may result into gradual organ and system failure and ultimately death.

The study is limited by its retrospective nature; it was also anticipated that some cases may not contain complete data and therefore was excluded from the study thus lowering the sample size. The study was carried out in a unit of one hospital instead of a multicenter study so generalization of the result of the study is limited. There is lack of funds that could be used to visit/contact each patient lost to follow-up to determine her status and the possible reasons. Despite all the limitations, the study has highlighted an important gap in the management of breast cancer patients which could serve as template in further research and in the generation of hypothesis. This knowledge would also be useful to influence policy towards breast cancer care.

In conclusion patients with breast cancer studied are aged between 27 and 73 years with a modal age of 41-50 years; they have poor educational background and present late to the hospital with advanced disease and have a high follow-up discontinuation rate. Attention to noncompliance with follow-up therapy and supportive care should be given to nonmarried women particularly those with metastasis and anaemia. Such attention might improve breast cancer outcomes in these patients. The hospital management should encourage and support its Hospice and Palliative Care Unit, particularly the community based patients' visits and consultations, to establish unbroken correspondence and links between the hospital and the patients and their relatives/families. This will reduce loss to follow-up. Breast cancer awareness campaigns and education by several groups and organizations in the country on screening methods, risk factors, self-breast examination, and symptoms of breast cancer should be supported and scaled up. This will encourage early presentation with early-stage disease and subsequently adherence with treatment and follow-up. Facilities for screening services in different localities that are affordable and accessible to women at risk of breast cancer should be made accessible to all women to facilitate early detection of breast cancer.

\section{Data Availability}

The data used to support the findings of this study are available from the corresponding author upon request.

\section{Ethical Approval}

The study involved no contact with the patients. However ethical approval for the study was obtained from the UI/UCH Ethics Committee.

\section{Disclosure}

The investigation were self-funded.

\section{Conflicts of Interest}

The authors declare no conflicts of interest.

\section{Authors' Contributions}

M. D. Dairo and D. B. Adamu designed the study, while D. B. Adamu and A. Ntekim did the data acquisition. D. B. Adamu and M. D. Dairo did the data analysis and reporting. D. B. Adamu, M. D. Dairo, and Y. A. Onimode wrote the draft manuscript. O. Ayeni provided general supervision and direction for the study. All authors approve of the final manuscript before publication.

\section{Acknowledgments}

The authors acknowledge the record staff of the University College Hospital Ibadan for the assistance in retrieving the case records of the patients.

\section{References}

[1] A. Ntekim, F. T. Nufu, and O. B. Campbell, "Breast cancer in young women in Ibadan, Nigeria," African Health Sciences, vol. 9, no. 4, pp. 242-246, 2009.

[2] M. T. Agyei-Frempong, F. N. Ghartey, S. Asante-Poku, and B. Wiafe-Addai, "A cross sectional view of estrogen receptors in 32 human breast cancer tissues in Ghana," Journal of Medical Sciences, vol. 8, no. 4, pp. 420-424, 2008.

[3] A. R. K. Adesunkanmi, O. O. Lawal, K. A. Adelusola, and M. A. Durosimi, "The severity, outcome and challenges of breast cancer in Nigeria," The Breast Journal, vol. 15, no. 3, pp. 399409, 2006.

[4] R. Sankaranarayanan, A. M. Budukh, and R. Rajkumar, "Effective screening programmes for cervical cancer in low- and middle-income developing countries," Bulletin of the World Health Organization, vol. 79, no. 10, pp. 954-962, 2001. 
[5] T. N. Elumelu, A. A. Adenipekun, A. A. Abdus-salam et al., "Pattern of Breast Cancer Metastasis at the Radiotherapy Clinic, Ibadan- A Ten Year Review," American Journal of Sciences, vol. 7, no. 7, pp. 906-912, 2001.

[6] C. A. Adebamowo and O. O. Ajayi, "Breast cancer in Nigeria.," West African Journal of Medicine, vol. 19, no. 3, pp. 179-191, 2000.

[7] O. B. da Lilly-Tariah, A. O. Somefun, and W. L. Adeyemo, "Current evidence on the burden of head and neck cancers in Nigeria.," Head \& neck oncology, vol. 1, p. 14, 2009.

[8] K. K. Ketiku, "The Pattern of Metastasis in Nigeria Breast cancer patients," Clinical Oncology, vol. 37, pp. 563-565, 1986.

[9] K. Adelusola, O. A. Fadiran, A. R. K. Adesunkanmi et al., "Breast cancer in Nigerian women," Nigeria Medical Practitioner, vol. 31, pp. 17-29, 1996.

[10] S. N. Anyanwu, "Breast cancer in eastern Nigeria: a ten year review," West African Journal of Medicine, vol. 19, no. 2, pp. 120125,2000

[11] C. A. Adebamowo, T. O. Ogundiran, A. A. Adenipekun et al., "Waist-hip ratio and breast cancer risk in urbanized Nigerian women," Breast Cancer Research, vol. 5, no. 2, pp. R18-24, 2003.

[12] E. A. Sule and D. Obaseki, "Pattern of histological types of breast cancer among various age groups in the niger delta," Journal of Medicine and Biomedical Research, vol. 13, no. 2, pp. 21-26, 2014.

[13] P. A. Bird, A. G. Hill, and N. Houssami, "Poor hormone receptor expression in East African breast cancer: evidence of a biologically different disease?" Annals of Surgical Oncology, vol. 15, no. 7, pp. 1983-1988, 2008.

[14] N. S. El Saghir, M. Seoud, M. K. Khalil et al., "Effects of young age at presentation on survival in breast cancer," BMC Cancer, vol. 6 , p. 194, 2006.

[15] C. Massimo, B. Thomas, G. Matthew et al., "Circulating tumor cells, disease progression, and survival in metastatic breast cancer," The New England Journal of Medicine, vol. 351, no. 8, pp. 781-791, 2004.

[16] T. Ogundiran, A. O. Adeoye, and A. F. Ademola, "Male breast cancer in Ibadan, Nigeria," Archives of Ibadan Medicine, vol. 9, no. 1\&2, pp. 16-19, 2008.

[17] D. Dogo, B. M. Ghali, N. Ali et al., "Male breast cancer in North eastern Nigeria," Nigerian Journal of Clinical Practice, vol. 9, no. 2, pp. 139-141, 2006.

[18] T. D. Hill, H. J. Khamis, J. E. Tyczynski, and H. J. Berkel, “Comparison of male and female breast cancer incidence trends, tumor characteristics, and survival," Annals of Epidemiology, vol. 15, no. 10, pp. 773-780, 2005.

[19] NCIC, "Canadian Cancer Statistics," 2006, http://publications .gc.ca/collections/Collection/CS2-37-2006E.pdf.

[20] F. Bray, P. McCarron, and D. M. Parkin, "The changing global patterns of female breast cancer incidence and mortality," Breast Cancer Research, vol. 6, no. 6, pp. 229-239, 2004.

[21] J. N. A. Clegg-Lamptey and W. Hodasi, "A study of breast cancer in korle bu teaching hospital: assessing the impact of health education," Ghana Medical Journal, vol. 41, no. 2, pp. 72-77, 2010.

[22] A. Gakwaya, J. B. Kigula-Mugambe, A. Kavuma et al., "Cancer of the breast: 5-Year survival in a tertiary hospital in Uganda," British Journal of Cancer, vol. 99, no. 1, pp. 63-67, 2008.

[23] T. Kene, V. Odigie, L. Yusufu, B. Yusuf, S. Shehu, and J. Kase, "Pattern of Presentation and Survival of Breast Cancer in a Teaching Hospital in North Western Nigeria," Oman Medical Journal, vol. 25, no. 2, pp. 104-107, 2010.
[24] C. S. Thomson, D. J. Hole, C. J. Twelves, D. H. Brewster, and R. J. Black, "Prognostic factors in women with breast cancer: Distribution by socioeconomic status and effect on differences in survival," Journal of Epidemiology and Community Health, vol. 55, no. 5, pp. 308-315, 2001.

[25] A. O. Adisa, O. A. Arowolo, A. A. Akinkuolie et al., "Metastatic breast cancer in a Nigerian tertiary hospit," African Health Sciences, vol. 11, no. 2, pp. 279-284, 2011.

[26] P. Misu, P. S. George, and A. Matthew, "Patient and Disease Related Factors Associated with loss to follow-up/Drop-outs of Cervical Cancer Patients: A Study at a Major Cancer Hospital in South India," Asian Pacific Journal of Cancer Prevention, vol. 11, p. 15291534, 2010.

[27] O. F. Ikpatt, T. Kuopio, and Y. Collan, "Proliferation in african breast cancer: Biology and prognostication in nigerian breast cancer material," Modern Pathology, vol. 15, no. 8, pp. 783-789, 2002.

[28] A. Mangardich, A. Marmoska-Dyga, D. Paul, G. Khan et al., "Loss to follow-up of cancer patients in the poorest district of the United States," Journal of Clinical Oncology, vol. 30, p. 6123, 2012.

[29] M. Kaku, A. Mathew, and B. Rajan, "Impact of socio-economic factors in delayed reporting and late-stage presentation among patients with cervix cancer in a major cancer hospital in South India," Asian Pacific Journal of Cancer Prevention, vol. 9, no. 4, pp. 589-594, 2008.

[30] A. K. Fink, J. Gurwitz, W. Rakowski, E. Guadagnoli, and R. A. Silliman, "Patient beliefs and tamoxifen discontinuance in older women with estrogen receptor-positive breast cancer," Journal of Clinical Oncology, vol. 22, no. 16, pp. 3309-3315, 2004.

[31] K. L. Kahn, E. C. Schneider, J. L. Malin, J. L. Adams, and A. M. Epstein, "Patient centered experiences in breast cancer: Predicting long-term adherence to tamoxifen use," Medical Care, vol. 45, no. 5, pp. 431-439, 2007.

[32] C. Onwusu, D. S. M. Buist, S. F. Terry et al., "Predictors of taxomifen discontinuation among older women with estrogen receptorpositive breast cancer," Journal of Clinical Oncology, vol. 26, pp. 549-555, 2008. 


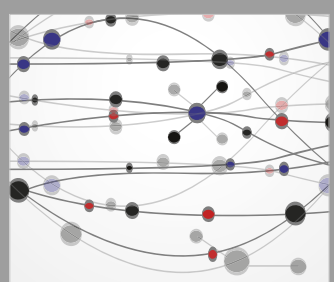

The Scientific World Journal
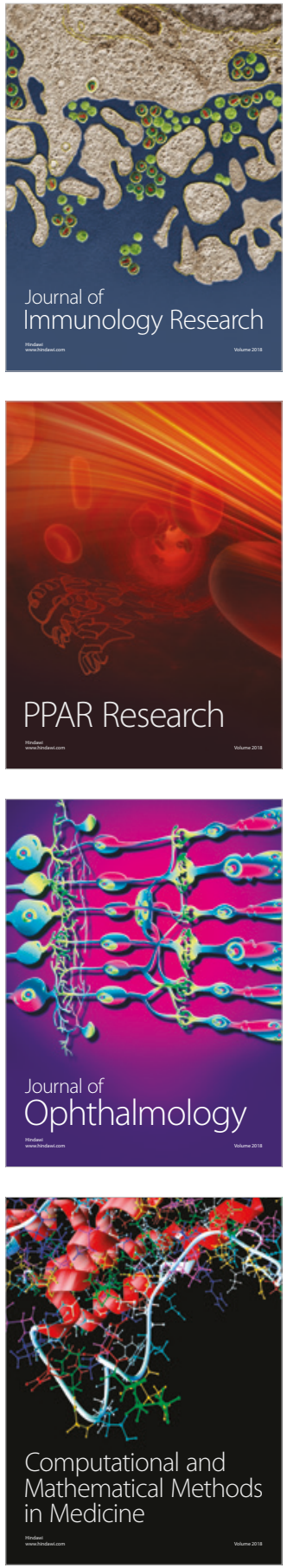

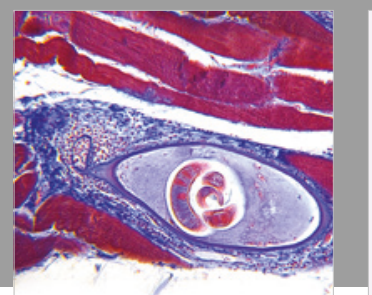

Gastroenterology Research and Practice

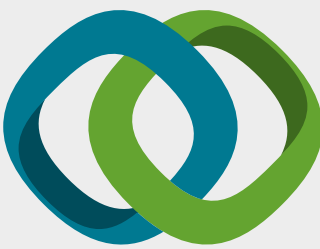

\section{Hindawi}

Submit your manuscripts at

www.hindawi.com
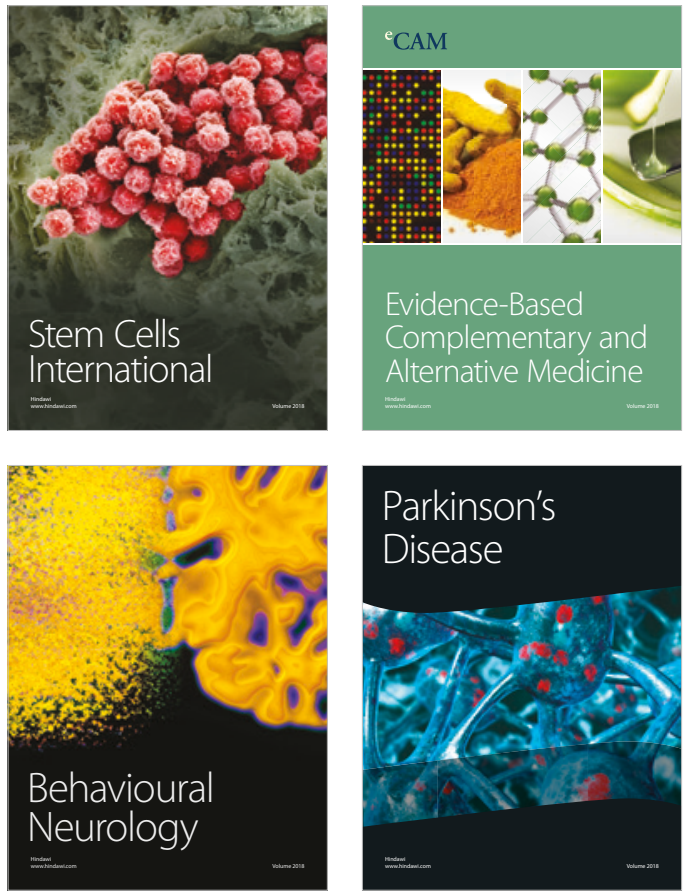

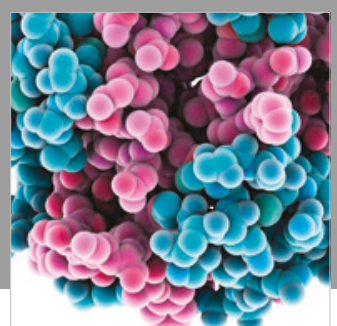

ournal of

Diabetes Research

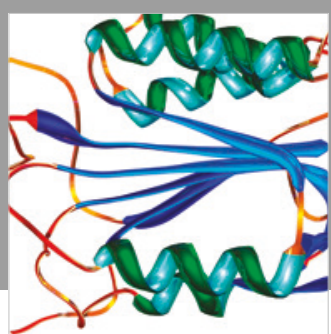

Disease Markers
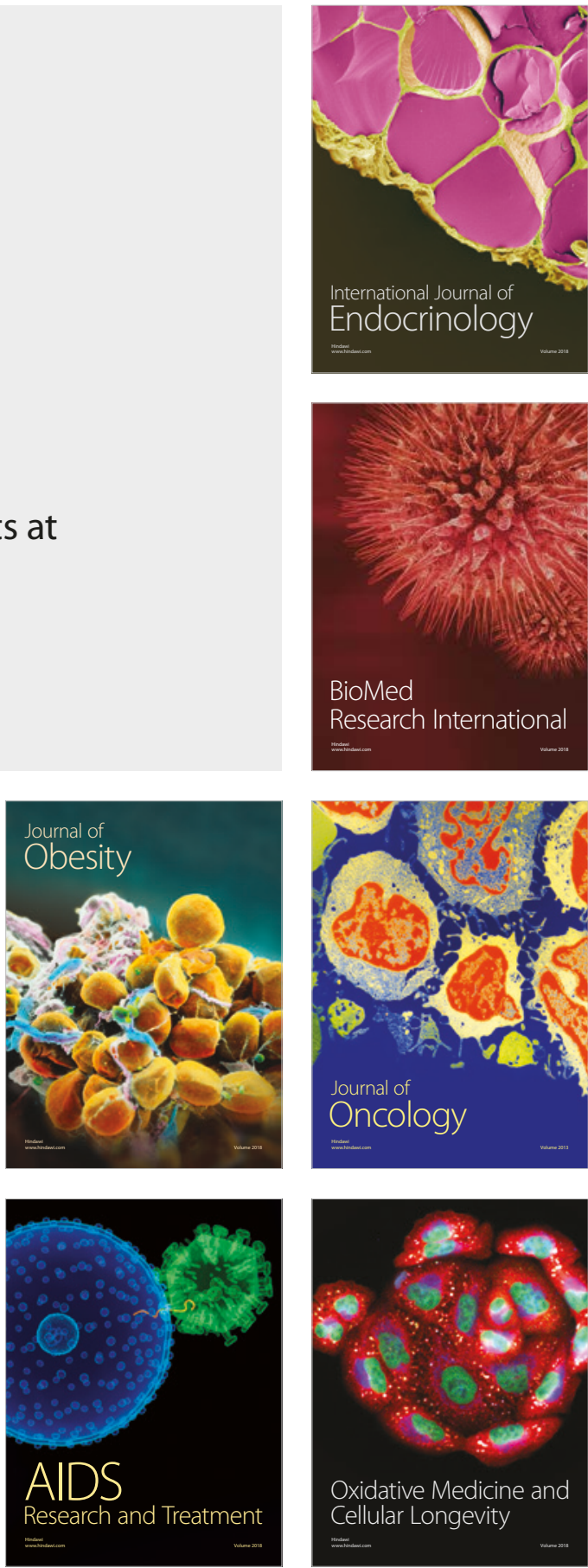